\title{
The mutational and copy number landscape of ovarian carcinosarcoma.
}

Imperial College London

D. Ennis ${ }^{1,2}$, G. Bryson ${ }^{3}$,S. Dowson ${ }^{1}$, R.M. Glasspool ${ }^{4}$, P. Roxburgh ${ }^{1,4}$, D. Millan ${ }^{3}$, A.V. Biankin ${ }^{1}$, I.A. McNeish ${ }^{1,2}$ and S.L. Cooke ${ }^{1}$ on behalf of the Scottish Genomes Partnership 1. Institute of Cancer Sciences, University of Glasgow, Glasgow, UK 2. Division of Cancer, Department of Surgery and Cancer, Imperial College, London ${ }^{3 \cdot}$ Department of Pathology, Queen Elizabeth University Hospital, Glasgow, UK ${ }^{4}$. Beatson West of Scotland Cancer Centre, Glasgow UK

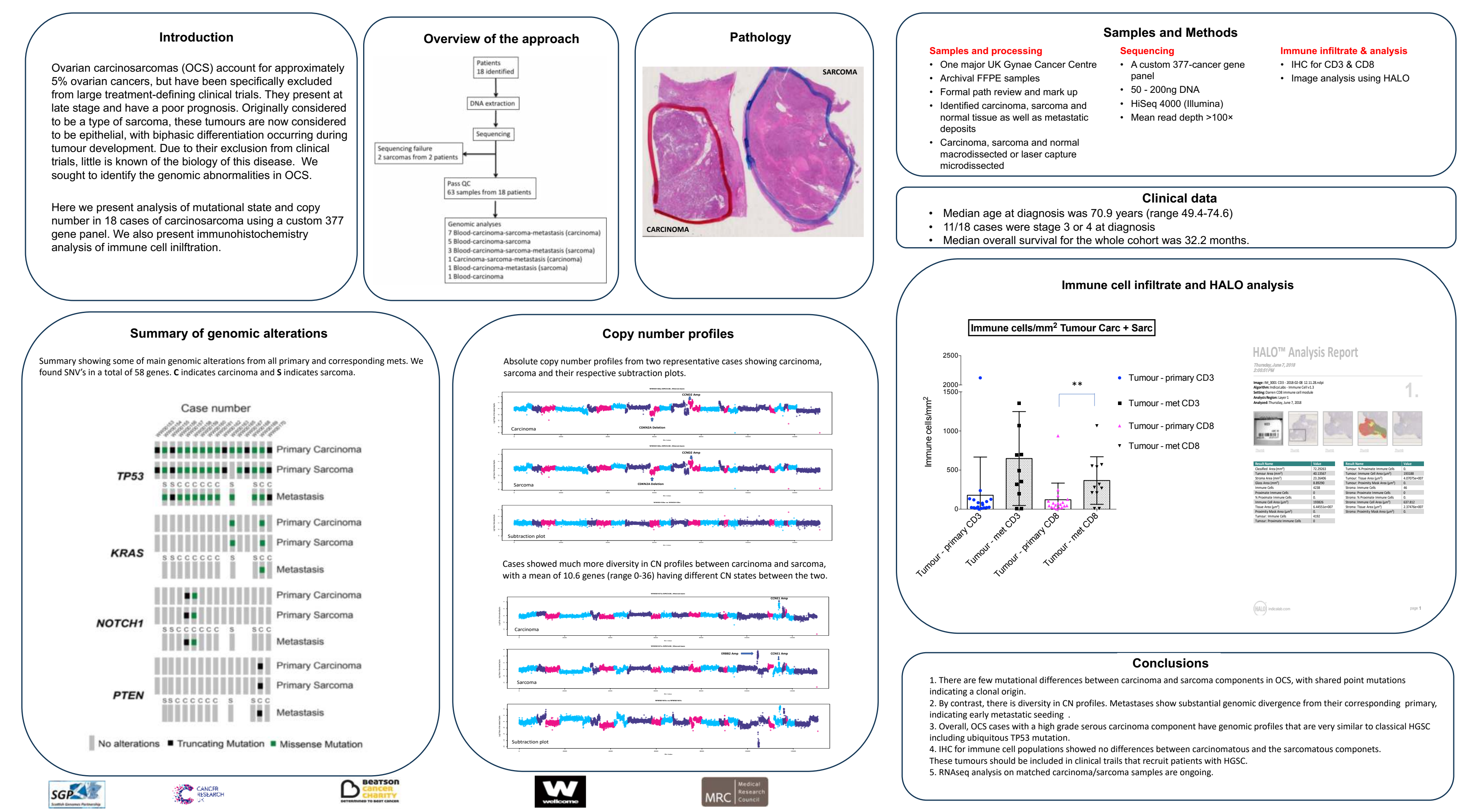

